Running head: Religious and existential well-being in families with Lynch Syndrome

The role of religious and existential well-being in families with Lynch Syndrome:

Prevention, family communication, and psychosocial adjustment

Bronwyn A. Morris ${ }^{1,2}$, Donald W. Hadley ${ }^{1,3}$, Laura M. Koehly ${ }^{1}$

${ }^{1}$ Social and Behavioral Research Branch, National Human Genome Research

Institute, Bethesda MD, USA

${ }^{2}$ Griffith Health Institute, Griffith University, Australia

${ }^{3}$ Office of the Clinical Director, National Human Genome Research Institute,

Bethesda MD, USA

Corresponding author: $\quad$ Dr Bronwyn Morris

Griffith Health Institute

Building G05 2.44

Gold Coast Campus

Griffith University Qld 4222

e-mail: b.morris@griffith.edu.au 


\begin{abstract}
This study explored the role of religious (RWB) and existential well-being (EWB) on psychosocial factors, support network characteristics, and screening practices in families with Lynch syndrome, also referred to as hereditary nonpolyposis colon cancer (HNPCC). Participants were individuals with Lynch syndrome associated cancers and their first-degree relatives at risk of inheriting an identified deleterious mutation. Analyses considered both family RWB and EWB norms and individual deviations from that norm. Analyses controlled for age, gender, cancer diagnosis, and network size. Higher family RWB was associated with increased depressive symptoms $(p<.05)$ and avoidant cognitions $(p<.05)$. Higher family-level EWB was related to decreased depression symptoms $(p<.001)$. Higher family EWB promoted fecal occult blood testing $(p<.01)$, and family communication about genetic counselling and testing $(p<.01)$. Analyses pointed to individual effects of EWB above and beyond family-level effects. Individuals with lower EWB than their family had lower perceived risk for colorectal cancer $(p<.05)$, communicated disease risk information to less family members $(p<.05)$, and were less likely to undergo recent colonoscopies $(p<.05)$. Participants with lower EWB than their family also had higher cancer worry $(p<.01)$ and increased depressive symptoms $(p<.001)$. Findings indicate the importance of assessing individuals within the context of their family network and being aware of family characteristics which may impact individual adjustment to disease risk. Interventions considering family-level factors may provide efficient pathways to improving psychosocial factors, screening practices, communication about disease risk and genetic testing, and cancer prevention. Keywords: Lynch Syndrome, Hereditary Nonpolyposis Colon cancer, Religious, Existential, Psychosocial, Cancer Prevention
\end{abstract}


Hereditary nonpolyposis colon cancer (HNPCC) is an inherited cancer susceptibility syndrome that significantly increases a person's risk of developing a number of cancers, most prominently colorectal and endometrial (Vasen, 2008). A number of other cancers are also observed at an increased incidence within families with HNPCC including ovarian, ureter and renal pelvis, stomach, and pancreatic (Lynch, Smyrk, \& Lynch, 1996). It has been estimated that the lifetime risk of developing colorectal cancer (CRC) in persons with HNPCC is between 40 to $70 \%$ (Vasen \& de Vos tot Nederveen Cappel, 2011). In addition, women with HNPCC are estimated to have a lifetime risk greater than $40 \%$ of developing endometrial cancer. (Aarnio, Mecklin, Aaltonen, Nystrom-Lahti, \& Jarvinen, 1995). A subset of families with HNPCC has been found to carry a mutation in a group of genes referred to as mismatch repair genes (MSH2, MLH1, MSH6, PMS2). This subset of families with identified mutations is referred to as having Lynch syndrome (Vasen \& Boland, 2005). The identification of a family mutation affords the ability to target family members through genetic testing who are at increased risk of developing cancers; thus facilitating prevention and detection strategies. In this view, families at increased risk of cancer and, in particular, preventable forms of cancer such as colorectal cancer, are an ideal context to target prevention strategies, and examine disease risk communication and psychosocial adjustment to cancer risk.

Collection, documentation and assessment of the family history of cancer is an effective approach to identify families with hereditary and familial forms of cancer (Kelly et al., 2007). This, in turn, facilitates the provision of genetic services including genetic testing of persons suspected of having a hereditary basis for their cancer. Should a mutation be discovered, genetic services can be provided to family members focusing preventative health practices on those at increased risk of 
developing cancer and relieving those at average risk. Research has provided convincing evidence that the morbidity and mortality associated with colorectal cancer can be significantly reduced in family members who actively participate in routine colorectal cancer screening practices (Jarvinen et al., 2009). However, there exists some evidence that the genetic testing can be a catalyst for psychological distress within the family (Ashida et al., 2008; Hadley et al., 2010). It is important to consider the psychosocial context of the family network system when examining individual coping and adjustment, particularly as family members negotiate their increased risk due to an inherited condition. This family context may impact individual level well-being, disease risk perceptions, and behaviors. For example, older family members may be particularly important in motivating younger family members to participate in CRC screening (Ashida et al., 2011). Older family members in extended family networks can also play an important role in providing younger generations with health information and social support (Ashida et al., 2011; Koehly et al., 2009). Furthermore, family social environments that are cohesive and families that share similar levels of cancer worry can be beneficial for individual members' psychological adjustment (Ashida et al., 2008).

There is a growing body of research showing that spirituality is an important component in promoting healthy psychosocial adjustment to the stressors associated with cancer (Holt, Oster, Clay, Urmie, \& Fouad, 2011; Laubmeier, Zakowski, \& Bair, 2004; Schreiber \& Brockopp, 2012). Spirituality can be deconstructed in terms of both religious and existential well-being (Paloutzian \& Ellison 1982). Religious wellbeing is defined by specific beliefs and organized worship within a social structure; whereas, existential well-being reflects a broader construct related to the individual having a transcendent relationship with a sacred entity and/or searching for life 
purpose or meaning (Holt et al., 2011; Koenig, 2001a). Tradition and culture commonly dictate that spiritual beliefs are formed within the family network, with core beliefs often being consistent between the individual and the family network (Stefanek, McDonald, \& Hess, 2005).

Spirituality can inform appraisal and coping processes when the individual is confronted with illness (Stefanek et al., 2005). For cancer survivors, religious and/or existential well-being has been linked with improved psychological well-being, hope and optimism, decreased anxiety and depression, greater perception of social support, and also provides a source of meaning and sense of purpose (Laubmeier et al., 2004). Spirituality and a self-forgiving attitude have also been linked to less mood disturbance and increased quality of life in women being treated for breast cancer (Romero et al., 2006). A study of African Americans with a BRCA1 mutation has also shown that individuals who place a high locus of control in God are less likely to adhere to clinical breast exams and mammographies (Kinney, Emery, Dudley, \& Croyle, 2002). It may be that spiritual coping results in a lower perceived risk of cancer for women with positive family histories of breast cancer (Quillin, McClish, Jones, Burruss, \& Bodurtha, 2006). Thus, resulting in fewer preventative behaviors such as screening for cancer. However, a higher rate of religious attendance has been shown to be associated with a greater utilization of breast cancer screening (Vasen, 2008). Thus, prompting the need to further investigate the multidimensional nature of spirituality and the facets of religion and spirituality that may impact on psychological well-being and healthy behaviors in relation to cancer (Kinney et al., 2002; Stefanek et al., 2005).

\section{Rationale and Aims}


The burgeoning research regarding HNPCC/Lynch syndrome families has begun to show the psychological impact of genetic susceptibility and the factors that promote healthy behaviors in at-risk individuals. Studies have also shown that spirituality plays a role in psychosocial adjustment after cancer (e.g., Holt et al., 2011; Laubmeier et al., 2004; Schreiber \& Brockopp, 2012) and impacts cancer-screening practices (Kinney et al., 2002; Vasen, 2008). However, investigations of how spirituality may affect adjustment to increased risks associated with hereditary cancers, such as those linked with Lynch Syndrome, are lacking in the current literature. Most studies assessing psychosocial factors associated with disease risk have focused on individual decision making and psychological and behavior responses. However, studies that investigate family level characteristics are emerging and may inform individual adjustment (Ashida et al., 2011; Ashida et al., 2008; Hadley et al., 2010). In order to take into account the context of hereditary disease in families at risk of HNPCC associated cancers, the current study investigated individual adjustment and health behavior within a family network structure. Furthermore, based on the concept that spirituality is constructed within the family environment (Stefanek et al., 2005), this study assessed spirituality on both a family level and an individual level. Individual spirituality was conceptualized and analyzed as a discrepancy from family mean scores.

Koenig et al. (2001b) proposed a theoretical model outlining that in the context of illness, religion will impact mental health, social support and health behaviors; and ultimately impact physical health. Importantly, this model (Koenig, 2001b) also accounts for genetic susceptibility and sociodemographic factors, such as age and gender. In this view, the current study was guided by the initial stages of Koenig's (2001b) theoretical model to investigate relationships between spirituality 
(comprised of religious and existential well-being) and: 1) psychological factors (perceived cancer risk and worry, depressive symptoms, and cancer-related distress);

2) family network characteristics (social support and family communication regarding risk and genetic testing); and 3) screening practices for CRC. The study hypothesizes that spirituality will promote healthy psychological outcomes (Holt et al., 2011; Laubmeier et al., 2004; Schreiber \& Brockopp, 2012). However, as there is a scarcity of relevant research, it is not yet known how spirituality may impact family network characteristics or preventative screening practices. Furthermore, the terms spiritual, religious, and existential are often used interchangeably in the literature (Stefanek et al., 2005), which limits predictions of how religious and existential well-being may differentially influence the proposed outcomes.

\section{Method}

\section{Participants and Procedure}

The current report is based on participants in a cohort study of individuals with Lynch syndrome and their biological family members at risk of inheriting the identified deleterious mutation. This study investigated the outcomes of genetic education, genetic counseling, and the option of genetic testing. The study has been described in detail in previous reports (Hadley et al., 2003). However in brief, persons suspected to have Lynch syndrome (e.g. tumors demonstrating micro-satellite instability, meeting the Amsterdam criteria or affected with multiple Lynch syndrome associated cancers) consented to participate and completed a baseline questionnaire assessing the variables of interest. Upon completion of the questionnaire participants received standardized genetic education for Lynch syndrome and client-centered counseling by either a Genetic Counselor (certified by the American Board of Genetic Counselors) or an Advanced Practice Nurse with training in cancer genetics. 
Following education and counseling, participants were given the option of undergoing genetic testing (sequencing of the mismatch repair genes associated with Lynch syndrome). Persons found to carry a disease causing mutation could invite their firstdegree biological relatives at risk to inherit the identified mutations to participate in the study and complete the same sequence of events. In some cases, relatives at greater biological distance (second-degree) were invited to participate if the intervening relative was deceased. Additional data were collected from these families through telephone interviews that elucidated the broad support network of participants. Family members who participated in the telephone interview included both biological and non-biological family members (spouses, in-laws, adopted and stepchildren). This study was originally approved by the Institutional Review Board of the National Human Genome Research Institute (95-HG-0165) and continues to be reviewed on an annual basis.

\section{Measures}

Information on age, gender, and previous cancer diagnoses was obtained through self-report assessment. Previously validated measures were used to assess the following variables with study participants:

Religious and Existential Well-being. The Spiritual Well-Being Scale (SWBS; Paloutzian \& Ellison 1982) was used to assess beliefs about spiritual meaning and satisfaction on two subscales of religious and existential well-being. Religious wellbeing (RWB) refers to sense of well-being in relationship to God (e.g., "I believe that God loves me and cares about me" and "I feel most fulfilled when I'm in close communion with God”); whereas, existential well-being (EWB) is concerned with overall sense of life purpose and satisfaction (e.g., "I feel that life is a positive experience" and "I feel a sense of well-being about the direction my life is headed 
in”). The SWBS is a 20-item survey that is responded to on a six-point Likert scale from strongly disagree (1) to strongly agree (6), with high scores indicating higher religious and existential well-being. The SWBS has been used in a number of illnessrelated contexts with strong internal consistency being previously shown (e.g., Ellison \& Smith, 1991) and also found in the current study (RWB subscale $\alpha=.97$; EWB subscale $\alpha=$.77).

Depression. The Center for Epidemiologic Studies Depression Scale (CESD; Radloff, 1977) is a 20-item survey used to assess symptoms of depression during the past week (e.g., “I was bothered by things that usually don’t bother me”). Participants responded to each item on a four-point Likert scale from none of the time (1) to most of the time (4), with high scores indicating higher depressive symptoms. Evidence of reliability and validity has been shown a number of contexts including cancer (e.g., Holt et al., 2011). Strong internal consistency was found in the current study ( $\alpha=.90$ ).

Distress. The Impact of Events Scale (IES; Horowitz, Wilner, \& Alvarez, 1979 ) is a 15- item survey used to assess subjective distress in the last seven days related to having a family history of cancer. Participants responded on a four-point Likert scale from not at all (1) to often (4), with high scores indicating greater distress. The IES and Revised IES have been validated widely across a variety of contexts (Hay, Buckley, \& Ostroff, 2005) and the IES has two subscales measuring intrusion (e.g., “Any reminder bought back feelings about it”) and avoidance ("I tried not to think about it”) related to a potentially traumatic event. Evidence of strong internal consistency was found in the current study (Intrusion $\alpha=.88$; Avoidance $\alpha=$ $.81)$.

Network Communication and Support. Information regarding participants’ networks was assessed through a telephone interview in which participants 
enumerated their network members. Specifically, participants were asked "When I say family, who do you think of? These can be people who are biologically related to you (like your children), people who are related to you but not through biological ties (like your spouse/partner or in-laws), or people who you consider to be family (like very close friends or coworkers).” Network size was reflected by the number of enumerated individuals. Network communication regarding cancer risk and social support was established through four questions: 1) "With whom in your family have you talked about genetic counseling and testing for HNPCC?”; 2) "With whom in your family have you shared your HNPCC risk status?”; 3) “Which members of your family help you, e.g., provide a meal, labor, ride to the doctor?”; 4) "Which members of your family support you emotionally?”. The numbers of enumerated network members were totaled to calculate communication regarding genetic counseling and testing, communication regarding disease risk, instrumental social support, and emotional social support.

Data Analysis

Data were analyzed with SPSS version 17.0 and HLM version 7.0. Prior to testing models, bivariate correlations were inspected to determine evidence of collinearity between predictor variables. Bivariate correlations did not exceed $r=.40$ and were well below suggested cut-offs for collinearity $(r=.80)$ (Tabachnick \& Fidell, 2007). In particular, the relationships between EWB and RWB $(r=.19)$ and family EWB and family RWB $(r=.16)$ were small.

The first set of analyses fitted seven hierarchical linear models evaluating the associations between the predictor variables and criterion variables of 1) perceived risk about CRC, 2) perceived risk about other cancers, 3) worry about CRC, 4) worry about other cancers, 5) depression, 6) intrusion, and 7) avoidance. The second set of 
analyses fitted four hierarchical nonlinear models assessing the associations between predictor variables and criterion variables of 1) network communication regarding genetic counseling/testing, 2) network communication about disease risk, 3) instrumental social support, and 4) emotional social support. As the criterion variables in the second set of analyses were based on a count of network members, a Poisson regression was used while controlling for network size. The final set of analyses fitted two hierarchical nonlinear models using logistic regression to evaluate the relationship between predictor variables and screening practices [whether the participant had undergone a fecal occult blood test (FOBT) and/or colonoscopy within the last six months].

In all fixed effects models, predictor variables included in level 1 accounted for individual religious and existential well-being, while controlling for age, gender and cancer diagnostic status. The level 1 religious and existential well-being scores were group mean centered; thus assessing discrepancies between individual scores and family mean scores. Predictor variables included in level 2 considered family mean scores for religious well-being and existential well-being, while controlling for the number of respondents taking part in the study within each family.

Maximum likelihood estimation was used to fit all of the models and statistical significance was assessed at 0.05 based on robust standard errors. For the first set of hierarchical linear models, coefficients and standard errors were examined to assess the strength of the relationship between predictor and outcome variables. For the second and third group of analyses based on hierarchical nonlinear models, odds ratios and 95\% confidence intervals were examined to assess the relationship between predictor and outcome variables; with an odds ratio (OR) greater than one representing a positive relationship and an odds ratio of less than one representing a 
negative relationship. Power analyses were conducted using SamplePower, with appropriate adjustments to account for the clustering of responses within families. Intra-class correlation coefficients (ICCs) for the continuous dependent variables considered in these analyses ranged between .02 and .17; for the categorical variables, ICCs ranged between .02 and .26. Using Cohen’s (1988) guidelines, there was sufficient power (.80) to detect medium effect sizes, after controlling for covariates, in these analyses.

\section{Results}

\section{Descriptive Statistics}

Participants were included in the current study if they consented to participate, completed the baseline questionnaire assessing the described variables of interest and participated in a telephone interview assessing their social network. This resulted in the inclusion of 123 individuals from 34 families. Participants' average age was 38.22 years $(S D=12.75)$, ranging from 18 to 72 . Participants were predominantly married (56.9\%) or single (29.3\%), were Caucasian (98.4\%), and 28.5\% of participants had a previous diagnosis of cancer. Just over half the sample were female (58.5\%), had a college/graduate degree (52.9\%), and were in full-time employment (59.3\%). On average, participants enumerated $10.64(S D=5.99)$ network members, ranging from 2 to 36. Participants generally reported their religious affiliation as Protestant (43.1\%), Catholic (35.0\%), Jewish (4.9\%), and no religious affiliation (13.8\%). On average, the number of respondents within each family was $3.62(S D=2.65$, minimum $=2$, maximum $=13$ ). Descriptive statistics for religious and spiritual well-being, and outcome variables are presented in Table I. Generally, mean scores indicated that the sample had high spiritual well-being, high perceived risk, low cancer worry, low depression, and low distress. 
Models

Results of the hierarchical linear models evaluating the associations between the predictor variables and perceived risk, worry about cancer, and psychosocial factors are displayed in Table II. Higher family RWB is associated with increased depressive symptoms and avoidance $(\beta=.106, p=.020)$; while a higher family EWB is related to fewer depressive symptoms $(\beta=-.679, p<.001)$. Individuals who have a smaller EWB score than their family score are more likely to have increased levels of worry about cancers other than CRC ( $\beta=-.074, p=.002)$, more depressive symptoms $(\beta=-.748, p<.001)$, and decreased perceived risk of colorectal cancer $(\beta=.026, p=$ $.012)$

Hierarchical nonlinear models using a Poisson regression were used to evaluate associations between predictor variables and network characteristics (Table III). All family network models controlled for network size, which was a significant predictor in each model. Higher family EWB was related to communicating with more family members regarding genetic counseling and testing $(\mathrm{OR}=1.032, p=$ .004); while having a lower individual EWB score than the family EWB score was associated with discussing disease risk with fewer family members (OR $=1.010, p=$ $.046)$.

Hierarchical nonlinear models with a logistic regression were used to evaluate associations between predictor variables and screening practices (Table IV).

Participants with a higher family EWB were more likely to undergo fecal occult blood testing in the last six months ( $\mathrm{OR}=1.308, p=.003)$; while individuals with a lower EWB score than the family norm were less likely to undergo colonoscopies (OR = 1.078, $p=.012)$.

\section{Discussion}


Synonymous with the initial stage of Koenig et al.’s (2001b) theoretical model, the results of the current study highlight that religious and existential wellbeing played varying roles in psychological factors, family network characteristics, and CRC screening practices. EWB appeared to be a particularly salient dimension of spiritual well-being in families at risk of Lynch syndrome. After taking age, gender, cancer diagnoses and network size into account, members of families with a higher EWB mean exhibited fewer depressive symptoms, a greater utilization of FOBT, and communicated with more family members about genetic counseling and testing. Members of families with a higher RWB norm reported more depressive symptoms and avoidant cognitions in relation to having a family history of cancer.

Traditionally an individualistic framework is often applied when assessing psychosocial outcomes and adjustment to disease. However, these results highlight the importance of assessing the individual within the context of the family network, particularly when investigating diseases with a hereditary component. From a developmental perspective, families may provide the foundation for individuals’ appraisal processes and coping responses to disease (Fox \& Ward, 2008). Individuals do not function in isolation and support network members may influence healthrelated decisions and psychosocial adjustment to disease (Kamibeppu et al., 2010; Kuenzler, Hodgkinson, Zindel, Bargetzi, \& Znoj, 2011; Peterson, 2005). Perhaps family existential well-being facilitated communal coping processes by providing guidance and a normative pattern of behavior for the individual confronted with genetic susceptibility to Lynch syndrome/HNPCC (Koenig, 2001a; Lyons, Mickelson, Sullivan, \& Coyne, 1998). Family members can share perceptions of risk and cancer worry and these social relationships within the family network can facilitate or impede an individual's adjustment to disease risk (Koehly et al., 2008). In this view, 
the results of the current study suggest that a family with an overall positive outlook on life and life purpose (high EWB) may provide an environment conducive to healthy adjustment (less depressive symptoms), family communication (about disease risk), and preventative screening for CRC (FOBT).

In conjunction with family levels of EWB, deviating from the family norm also impacted individual outcome variables. For example, participants with lower EWB than their family had a lower perceived risk of CRC, communicated about their disease risk information with fewer network members, and were less likely to undergo preventative screening practices such as colonoscopies. Participants with lower EWB than their family also reported more depressive symptoms and had significantly higher levels of cancer worry. In other words, individuals who have a decreased positive outlook or less life purpose compared to their family norm tend not to perceive cancer risk, do not talk about disease in their family, nor participate in screening, but they also have high levels of cancer worry and depressive symptoms. These results are perhaps indicative of denial or avoidance regarding family history of cancer. Whilst denial may be an effective coping strategy in the short-term, extended periods of denial may lead to distress and failure to engage in appropriate medical interventions (Folkman, 2010; Lazarus \& Folkman, 1984); which may be reflected in current study participants who had high levels of worry, depressive symptoms, inertia regarding cancer screening, lack of family communication regarding family disease risk, and a decreased positive outlook on life compared to their family.

To date, there is a lack of clarity defining the multidimensional nature of religious, existential, and spirituality well-being (Stefanek et al., 2005), and these terms are often used interchangeably within the literature. In the current study, the lack of collinearity between EWB and RWB, and the salience of EWB in the models 
indicate that EWB and RWB represent different constructs. EWB represented life purpose and meaning, comprising of scale items such as "I feel that life is a positive experience” and "I feel a sense of well-being about the direction my life is headed in," whereas, RWB scale items were directed toward prayer and a relationship with God (Paloutzian \& Ellison 1982). The conceptual distinction between EWB and RWB has been highlighted in a previous study regarding career and life development (Perrone, Webb, Wright, Jackson, \& Ksiazak, 2006). The results of this study revealed that, while RWB was not related to any factors, EWB was positively associated with job and life satisfaction (Perrone et al., 2006). Perrone at al. suggest that EWB provides life direction and meaning, while RWB or attending church does not necessarily correlate with life satisfaction. Furthermore, in the context of disease risk in the current study, members from families with higher family RWB reported more depressive symptoms and avoidant cognitions. Perhaps discussion about the potential genetic nature of their disease may have conflicted with family religious doctrine (Botoseneanu, Alexander, \& Banaszak-Holl, 2011; Bowen, Singal, Eng, Crystal, \& Burke, 2003), resulting in individuals reporting increased depressive and avoidant symptomatology when they were within families exhibiting a strong relationship with God.

\section{Strengths, Limitations, and Future Directions}

The results of the current study emphasize the salience of spiritual well-being for individuals diagnosed with Lynch syndrome and their biological family members who are at risk of inheriting the deleterious family mutation. This study also provides a unique contribution to the religious and spirituality literature by highlighting the importance of assessing both individual and family-level spiritual well-being. Firstly, family-level RWB and EWB were shown to influence individual adjustment, family 
communication, and health-related decision processes. Secondly, discrepancies between individual EWB and family mean scores also played a role in individual outcome variables. These results were guided by the initial stages of the model proposed by Koenig et al. (2001b) showing the impact of spiritual well-being on mental health, social support, and health behaviors. Future study can investigate the further impact of these factors on physical health in the context of hereditary disease.

These results have important implications for intervention and prevention in the context of hereditary and familial cancers. For example, in order to design efficient intervention pathways, interventions can be broadened to include the family network rather than merely targeting the individual. The results of the current study emphasize that individuals with disparate life outlooks from their family, namely lower EWB, are less likely to perceive that they have a risk, are less likely to communicate about disease risk, and are less likely to undergo screening. Therefore, targeting appropriate family members is essential in order to efficiently disseminate information and encourage healthy behaviors within the network. This is especially important within the context of genetic testing, in which concerns regarding confidentiality prevent health professionals from informing relevant biological kin about a family member's mutation status. Therefore, factors that assist in family communication and also barriers that prevent these health messages being disseminated through key members within such families can be identified. For example, as shown in the current study and previous literature, key communicators within families could be identified as family members who have a cancer history, those who have a consistent EWB with their family and are within families that have a high EWB, and female first- and second-degree relatives. 
The results also indicate that clinicians may need to be cognizant of families that have high RWB and provide psychosocial care for individuals undergoing genetic testing. While religious involvement has been shown to be a protective resource in an illness context, the results of the current study and previous literature have indicated the potential influence that religion may have on poorer well-being, maladaptive coping strategies, and unhealthy behaviors (Chatters, 2000; Ellison \& Levin, 1998). For example, social norms associated with religious doctrine can create feelings of guilt, discouragement of certain medical treatments, and maladaptive coping reflected through locus of control solely centered on God (Chatters, 2000; Ellison \& Levin, 1998). Whereas, the current study highlights the association between healthy adjustment and existential well-being. On an individual level, genetic health educators can include an existential approach during counseling in an attempt to help individuals to identify sources of meaning in their life and promote psychological well-being. On a broader community level, perhaps religious groups could be addressed and encouraged to promote healthy practices regarding preventable cancers within their communities.

Whilst the study results provide evidence for the influence of religion and existential well-being in families affected by Lynch syndrome, participants were predominantly Caucasian and reported affiliations with Christian-based religions (e.g., Catholic and Protestant). Also, the items contained in the SWBS are directed toward Christian-based religions. Therefore, results cannot be generalized to other cultural and religious contexts and further study needs to be conducted to determine if the findings apply across different contexts. The cross-sectional nature of the study is also associated with customary limitations, including the inability to attribute a predictive nature to religious and existential well-being on the outcome variables. For 
example, family EWB may provide an environment conducive to participating in screening practices such as colonoscopy and FOBT. Conversely, this relationship may also indicate that undergoing preventative health behaviors is a catalyst for thinking about the meaning and purpose of life. Further longitudinal study can address these issues related to cross-sectional data.

\section{Conclusion}

The results of the current study provide a unique contribution to the literature investigating the role of spiritual well-being in the context of heritable diseases and highlight the salience of existential well-being in promoting healthy behaviors. Understanding the multidimensional nature of spirituality is essential when differentiating potential influences imposed on an individual facing hereditary risks for cancer (Crane, 2009; Stefanek et al., 2005). Importantly, this study also provides evidence for assessing an individual within the context of their family network, particularly for individuals with mutations increasing risk to develop cancer and relatives contemplating genetic testing. Future intervention studies that take family environment into account may identify efficient pathways to improving psychosocial outcomes and screening practices. Importantly, improving communication about disease risk and genetic testing is essential within families where Lynch Syndrome is present. Family communication and screening practices are important steps in encouraging sustainable preventative health practices that reduce the risk of disease and promote health and well-being. 
Acknowledgments: This research was supported by the Division of Intramural Research Program of the National Human Genome Research Institute (ZO1HG200335, PI: Koehly). 


\section{References}

Aarnio, M., Mecklin, J., Aaltonen, L. A., Nystrom-Lahti, M., \& Jarvinen, H. J. (1995). Life-time risk of different cancers in Hereditary Non-Polyposis Colorectal Cancer (HNPCC) Syndrome. International Journal of Cancer, 64, 430-433.

Ashida, S., Hadley, D. W., Goergen, A. F., Skapinsky, K. F., Devlin, H. C., \& Koehly, L. M. (2011). The importance of older family members in providing social resources and promoting cancer screening in families with a hereditary cancer syndrome. Gerontologist, 51, 833-842.

Ashida, S., Hadley, D. W., Vaughn, B. K., Kuhn, N. R., Jenkins, J. F., \& Koehly, L. M. (2008). The impact of familial environment on depression scores after genetic testing for cancer susceptibility. Clinical Genetics, 75, 43-49.

Botoseneanu, A., Alexander, J. A., \& Banaszak-Holl, J. (2011). To test or not to test? The role of attitudes, knowledge, and religious involvement among U.S. adults on intent-to-obtain adult genetic testing. Health Education \& Behavior, 38, 617-628.

Bowen, D. J., Singal, R., Eng, E., Crystal, S., \& Burke, W. (2003). Jewish identity and intentions to Ootain breast cancer screening. Cultural Diversity and Ethnic Minority Psychology, 9, 79-87.

Chatters, L. M. (2000). Religion and health: Public health research and practice. Annual Review of Public Health, 21, 335-367.

Cohen, D. S. (1988). Statistical power analyses for the behavioral sciences (2nd ed.). New Jersey, USA: Lawrence Erlbaum Associates.

Crane, J. N. (2009). Religion and cancer: Examining the possible connections. Journal of Psychosocial Oncology, 27, 469-486. 
Ellison, C. G., \& Levin, J. S. (1998). The religion-health connection: Evidence, theory, and future directions. Health Education \& Behavior, 25, 700-720.

Ellison, C. W., \& Smith, J. (1991). Toward an integrative measure of health and wellbeing. Journal of Psychology and Theology, 19, 35-48.

Folkman, S. (2010). Stress, coping, and hope. Psycho-Oncology, 19, 901-908.

Fox, N. J., \& Ward, K. J. (2008). What are health identities and how may we study them? Sociology of Health \& Illness, 30, 1007-1021.

Hadley, D. W., Ashida, S., Jenkins, J. F., Martin, J. C., Calzone, K. A., Kuhn, N. R. et al. (2010). Generation after generation: exploring the psychological impact of providing genetic services through a cascading approach. Genetics in Medicine, 12, 808-815.

Hadley, D. W., Jenkins, J., Dimond, E., Nakahara, K., Grogan, L., Liewehr, D. J. et al. (2003). Genetic counseling and testing in families with Hereditary Nonpolyposis Colorectal Cancer. Archives of Internal Medicine, 163, 573582.

Hay, J. L., Buckley, T. R., \& Ostroff, J. S. (2005). The role of cancer worry in cancer screening: A theoretical and empirical review of the literature. PsychoOncology, 14, 517-534.

Holt, C. L., Oster, R. A., Clay, K. S., Urmie, J., \& Fouad, M. (2011). Religiosity and physical and emotional functioning among African American and White colorectal and lung cancer patients. Journal of Psychosocial Oncology, 29, 372-393.

Horowitz, M., Wilner, N., \& Alvarez, W. (1979). Impact of Event Scale: A measure of subjective stress. Psychosomatic Medicine, 41, 209-218. 
Jarvinen, H. J., Renkonen-Sinisalo, L., Aktan-Collan, K., Peltomaki, P., Aaltonen, L. A., \& Mecklin, J. P. (2009). Ten years after mutation testing for Lynch syndrome: cancer incidence and outcome in mutation-positive and mutationnegative family members. Journal of Clinical Oncology, 27, 4793-4797.

Kamibeppu, K., Sato, I., Honda, M., Ozono, S., Sakamoto, N., Iwai, T. et al. (2010). Mental health among young adult survivors of childhood cancer and their siblings including posttraumatic growth. Journal of Cancer Survivorship, 4, 303-312.

Kelly, K. M., Shedlosky-Shoemaker, R., Porter, K., Remy, A., DeSimone, P., \& Andrykowski, M. A. (2007). Cancer family history reporting: Impact of method and psychosocial factors. Journal of Genetic Counseling, 16, 373-382.

Kinney, A. Y., Emery, G., Dudley, W. N., \& Croyle, R. T. (2002). Screening behaviors among African American women at high risk for breast cancer: Do beliefs about God matter? Oncology Nursing Forum, 29, 835-843.

Koehly, L. M., Peters, J. A., Kenen, R., Hoskins, L. M., Ersig, A. L., Kuhn, N. R. et al. (2009). Characteristics of health information gatherers, disseminators, and blockers within families at risk of hereditary cancer: implications for family health communication interventions. American Journal of Public Health, 99, 2203-2209.

Koehly, L. M., Peters, J. A., Kuhn, N., Hoskins, L., Letocha, A., Kenen, R. et al. (2008). Sisters in hereditary breast and ovarian cancer families: communal coping, social integration, and psychological well-being. Psycho-Oncology, 17, 812-821.

Koenig, H. G. (2001a). Religion and medicine II: Religion, mental health, and related behaviors. International Journal of Psychiatry in Medicine, 31, 97-109. 
Koenig, H. G. (2001b). Religion and medicine III: Devleoping a theoretical model. International Journal of Psychiatry in Medicine, 31, 199-216.

Kuenzler, A., Hodgkinson, K., Zindel, A., Bargetzi, M., \& Znoj, H. J. (2011). Who cares, who bears, who benefits? Female spouses vicariously carry the burden after cancer diagnosis. Psychology and Health, 26, 337-352.

Laubmeier, K. K., Zakowski, S. G., \& Bair, J. P. (2004). The role of spirituality in the psychological adjustment to cancer: A test of the Transactional Model of Stress and Coping. International Journal of Behavioral Medicine, 11, 48-55.

Lazarus, R. S., \& Folkman, S. (1984). Stress, Appraisal, and Coping. New York: Springer Publishing Company.

Lynch, H. T., Smyrk, T., \& Lynch, J. F. (1996). Overview of natural history, pathology, molecular genetics and managemtn of HNPCC (Lynch Syndrome). International Journal of Cancer, 69, 38-43.

Lyons, R. F., Mickelson, K. D., Sullivan, M. J. L., \& Coyne, J. C. (1998). Coping as a communal process. Journal of Social and Personal Relationships, 15, 579605.

Paloutzian , R. F., \& Ellison , C. W. (1982). Loneliness, spiritual well-being and the quality of life. In L. A. Peplau \& D. Perman (Eds.), Loneliness: A sourcebook of current theory, research and therapy (pp. 224-237). New York: Wiley.

Perrone, K. M., Webb, L. K., Wright, S. L., Jackson, Z. V., \& Ksiazak, T. M. (2006). Relationship of spirituality to work and family roles and life satisfaction among gifted adults. Journal of Mental Health Counseling, 28, 253-268.

Peterson, S. K. (2005). The role of the family in genetic testing: Theoretical perspectives, current knowledge, and future directions. Health Education \& Behavior, 32, 627-639. 
Quillin, J. M., McClish, D. K., Jones, R. M., Burruss, K., \& Bodurtha, J. N. (2006). Spiritual coping, family history, and perceived risk for breast cancer-Can we make sense of it? Journal of Genetic Counseling, 15, 449-460.

Radloff, L. S. (1977). The CES-D Scale: A self-report depression scale for research in the general population. Applied Psychological Measurement, 1, 385-401.

Romero, C., Kalidas, M., Elledge, R., Chang, J., Liscum, K. R., \& Friedman, L. C. (2006). Self-forgiveness, spirituality, and psychological adjustment in women with breast cancer. Journal of Behavioral Medicine, 29, 29-36.

Schreiber, J. A., \& Brockopp, D. Y. (2012). Twenty-five years later-what do we know about religion/spirituality and psychological well-being among breast cancer survivors? A systematic review. Journal of Cancer Survivorship, 6, 82-94.

Stefanek, M., McDonald, P. G., \& Hess, S. A. (2005). Religion, spirituality and cancer: Current status and methodological challenges. Psycho-Oncology, 14, 450-463.

Tabachnick, B., \& Fidell, L. (2007). Using multivariate statistics (5th ed.). Boston Pearson/Allyn \& Bacon.

Vasen, H. F. A. (2008). Can the identification of high risk groups increase the effectiveness of colon cancer screening programmes? Z Gastroenterol, 46, 541-542.

Vasen, H. F. A., \& Boland, C. R. (2005). Progress in Genetic Testing, Classification, and Identification of Lynch Syndrome. Journal of the American Medical Association, 293, 2028-2030.

Vasen, H. F. A., \& de Vos tot Nederveen Cappel, W. H. (2011). Lynch syndromehow should colorectal cancer be managed? Nature Reviews Gastroenterology and Hepatology, 8, 184-186. 
Table I

Descriptive Statistics for Religious and Existential Well-being, and Outcome Variables

\begin{tabular}{lcc}
\hline & Scale range* & $M(S D)$ \\
\hline Religious well-being - individual & $10-60$ & $42.74(16.23)$ \\
Existential well-being - individual & $10-60$ & $50.66(6.92)$ \\
Religious well-being - family & $10-60$ & $43.90(13.24)$ \\
Existential well-being - family & $10-60$ & $51.14(3.62)$ \\
Perceived Risk of Cancer - CRC & $1-5$ & $4.31(0.83)$ \\
Perceived Risk of Cancer - other cancers & $1-5$ & $4.14(1.03)$ \\
Worry about Cancer - CRC & $3-12$ & $4.70(1.47)$ \\
Worry about Cancer - other cancers & $3-12$ & $4.12(1.23)$ \\
Depression & $0-60$ & $9.24(7.73)$ \\
Intrusion & $0-35$ & $6.67(7.03)$ \\
Avoidance & $0-40$ & $7.29(6.91)$ \\
Communicating Genetic Counseling and Testing & - & $7.21(3.90)$ \\
information & & \\
Communicating Disease Risk & - & $7.85(3.91)$ \\
Instrumental Social Support & - & $6.14(3.93)$ \\
Emotional Social Support & - & $6.54(4.57)$ \\
\hline FOBT in the past 6 months & - & 10.6 \\
Colonoscopy in the past 6 months & & 31.7 \\
\hline Note* possbe & & \\
\hline
\end{tabular}

Note. * possible range of scores on this measure, $M=$ Mean, $S D=$ Standard deviation, $\mathrm{CRC}=$

Colorectal cancer, FOBT $=$ Fecal Occult Blood Test 
Table II

Association of Religious and Existential Well-being with Psychological Factors

\begin{tabular}{|c|c|c|c|c|c|c|c|c|c|c|c|c|c|c|}
\hline & \multicolumn{4}{|c|}{ Perceived Risk of Cancer } & \multicolumn{4}{|c|}{ Worry about Cancer } & \multirow{2}{*}{\multicolumn{2}{|c|}{$\begin{array}{l}\text { CES-D } \\
\text { Depression }\end{array}$}} & \multicolumn{4}{|l|}{ IES } \\
\hline & \multicolumn{2}{|l|}{ CRC } & \multicolumn{2}{|c|}{ Other cancers } & \multicolumn{2}{|l|}{ CRC } & \multicolumn{2}{|c|}{ Other cancers } & & & \multicolumn{2}{|c|}{ Intrusion } & \multicolumn{2}{|c|}{ Avoidance } \\
\hline & $\begin{array}{l}\text { Beta } \\
\text { Coeff }\end{array}$ & $S E$ & $\begin{array}{l}\text { Beta } \\
\text { Coeff }\end{array}$ & $S E$ & $\begin{array}{l}\text { Beta } \\
\text { Coeff }\end{array}$ & $S E$ & $\begin{array}{l}\text { Beta } \\
\text { Coeff }\end{array}$ & $S E$ & $\begin{array}{l}\text { Beta } \\
\text { Coeff }\end{array}$ & $S E$ & $\begin{array}{l}\text { Beta } \\
\text { Coeff }\end{array}$ & $S E$ & $\begin{array}{l}\text { Beta } \\
\text { Coeff }\end{array}$ & $S E$ \\
\hline \multicolumn{15}{|l|}{ Level 1} \\
\hline Age & -.005 & .005 & .001 & .008 & $-.019 *$ & .008 & .007 & .011 & .030 & .030 & -.051 & .060 & -.097 & .067 \\
\hline Female & .095 & .137 & .039 & .163 & .117 & .282 & .171 & .199 & .870 & 1.393 & $2.393^{*}$ & 1.104 & -1.253 & 1.219 \\
\hline Cancer Dx & -.405 & .224 & $.964 * * *$ & .210 & $1.104 * * *$ & .303 & $.727 *$ & .301 & -1.033 & .802 & $3.097 *$ & 1.319 & .468 & 1.266 \\
\hline RWB & -.012 & .006 & .001 & .007 & -.014 & .009 & .010 & .009 & .043 & .056 & .028 & .041 & .047 & .048 \\
\hline EWB & $.026 *$ & .010 & -.015 & .014 & -.039 & .021 & $-.074 * *$ & .024 & $-.748 * * *$ & .082 & -.190 & .138 & -.117 & .096 \\
\hline \multicolumn{15}{|l|}{ Level 2} \\
\hline No. of Respondents & -.002 & .022 & .025 & .021 & -.012 & .047 & $.067 *$ & .028 & -.071 & .112 & -.064 & .321 & -.053 & .132 \\
\hline Family RWB & -.012 & .007 & .003 & .012 & .012 & .014 & .001 & .010 & $.106 *$ & .043 & .093 & .048 & $.111 *$ & .050 \\
\hline Family EWB & -.013 & .020 & -.022 & .023 & -.041 & .032 & -.026 & .028 & $-.679 * * *$ & .158 & -.138 & .223 & -.243 & .149 \\
\hline
\end{tabular}

Note. ${ }^{*} p<.05,{ }^{* *} p<.01,{ }^{* * *} p<.001$, CRC = Colorectal cancer, RWB = Religious Well-being, EWB = Existential Well-being, CES-D = Center for Epidemiologic

Studies Depression Scale, IES = Impact of Event Scale, Coeff = Coefficient, $S E=$ Standard Error. 
Table III

Association of Religious and Existential Well-being with Family Network Characteristics

\begin{tabular}{|c|c|c|c|c|c|c|c|c|}
\hline & \multicolumn{8}{|c|}{ Family Network characteristics (controlling for size) } \\
\hline & \multicolumn{2}{|c|}{$\begin{array}{l}\text { Communicating Genetic } \\
\text { Counseling and Testing } \\
\text { information }\end{array}$} & \multicolumn{2}{|c|}{$\begin{array}{l}\text { Communicating Disease } \\
\text { Risk }^{\#}\end{array}$} & \multicolumn{2}{|c|}{$\begin{array}{l}\text { Instrumental Social } \\
\text { Support }^{\#}\end{array}$} & \multicolumn{2}{|c|}{$\begin{array}{l}\text { Emotional Social } \\
\text { Support }^{\#}\end{array}$} \\
\hline & OR & $(95 \% \mathrm{CI})$ & OR & $(95 \% \mathrm{CI})$ & OR & $(95 \% \mathrm{CI})$ & OR & $(95 \% \mathrm{CI})$ \\
\hline Level 1 & & & & & & & & \\
\hline Age & 1.003 & $(0.996,1.010)$ & 1.002 & $(0.997,1.007)$ & 0.996 & $(0.990,1.002)$ & 1.002 & $(0.994,1.010)$ \\
\hline Female & 0.889 & $(0.786,1.004)$ & 0.929 & $(0.847,1.020)$ & $0.834^{*}$ & $(0.699,0.994)$ & 0.788* & $(0.656,0.946)$ \\
\hline Cancer Dx & $1.224 *$ & $(1.020,1.470)$ & $1.170^{*}$ & $(1.017,1.346)$ & $0.740 *$ & $(0.573,0.956)$ & 0.972 & $(0.768,1.230)$ \\
\hline RWB & 0.998 & $(0.993,1.004)$ & 1.000 & $(0.996,1.004)$ & 1.002 & $(0.995,1.009)$ & 0.999 & $(0.993,1.005)$ \\
\hline EWB & 1.011 & $(0.997,1.025)$ & $1.010 *$ & $(1.000,1.020)$ & 1.009 & $(0.997,1.023)$ & 1.009 & $(0.998,1.020)$ \\
\hline Network Size & $1.039 * * *$ & $(1.025,1.054)$ & $1.042 * * *$ & $(1.027,1.056)$ & $1.044^{* * *}$ & $(1.023,1.066)$ & $1.042 * *$ & $(1.015,1.068)$ \\
\hline Level 2 & & & & & & & & \\
\hline No. of Respondents & $1.029 * *$ & $(1.010,1.048)$ & $1.029 * * *$ & $(1.016,1.042)$ & 0.976* & $(0.955,0.997)$ & $1.044 *$ & $(1.008,1.082)$ \\
\hline Family RWB & 1.004 & $(0.999,1.010)$ & 1.001 & $(0.996,1.006)$ & 1.007 & $(0.998,1.016)$ & 0.999 & $(0.987,1.011)$ \\
\hline Family EWB & $1.032 * *$ & $(1.011,1.053)$ & 1.022 & $(0.995,1.049)$ & 1.017 & $(0.988,1.047)$ & 1.009 & $(0.980,1.039)$ \\
\hline
\end{tabular}

Note. ${ }^{*} p<.05,{ }^{* *} p<.01,{ }^{* * *} p<.001$, \#Over dispersed and Poisson, RWB $=$ Religious Well-being, EWB = Existential Well-being, OR = Odds ratio, CI = Confidence Interval 
Table IV

Association of Religious and Existential Well-being with Screening Practices

\begin{tabular}{|c|c|c|c|c|}
\hline & \multicolumn{4}{|c|}{ Screening Practices } \\
\hline & \multicolumn{2}{|l|}{ FOBT $^{\#}$} & \multicolumn{2}{|c|}{ Colonoscopy $^{\#}$} \\
\hline & OR & $(95 \% \mathrm{CI})$ & OR & $(95 \% \mathrm{CI})$ \\
\hline \multicolumn{5}{|l|}{ Level 1} \\
\hline Age & 1.024 & $(0.997,1.050)$ & 0.995 & $(0.961,1.031)$ \\
\hline Female & 0.848 & $(0.325,2.208)$ & 0.861 & $(0.490,1.514)$ \\
\hline Cancer Dx & 1.996 & $(0.675,5.902)$ & $3.076 *$ & $(1.137,8.325)$ \\
\hline RWB & 1.012 & $(0.948,1.079)$ & 0.976 & $(0.938,1.014)$ \\
\hline EWB & 1.045 & $(0.945,1.155)$ & 1.078* & $(1.017,1.142)$ \\
\hline \multicolumn{5}{|l|}{ Level 2} \\
\hline No. of Respondents & 0.998 & $(0.852,1.170)$ & 0.982 & $(0.844,1.142)$ \\
\hline Family RWB & 1.046 & $(0.996,1.099)$ & 1.036 & $(0.987,1.088)$ \\
\hline Family EWB & $1.308 * *$ & $(1.104,1.549)$ & 1.188 & $(0.982,1.437)$ \\
\hline
\end{tabular}

Note. ${ }^{*} p<.05, * * p<.01, * * * p<.001,{ }^{*}$ Over dispersed and Bernoulli, RWB = Religious Well-being,

EWB $=$ Existential Well-being, FOBT $=$ Fecal Occult Blood Test, OR = Odds ratio, CI = Confidence Interval. 